\title{
humanidades
}

Revista humanidades

Enero-junio, 2016 • Volumen 6, número 1・ISSN 2215-3934・pp. 1-48

\section{El estudio de la muerte en el islam: Una filosofía de la vida}

DOI: http://dx.doi.org/10.15517/h.v6i1.25118

\section{Roberto Marín Guzmán}

Doctor en Historia del Medio Oriente y en Estudios Islámicos. Profesor en la Escuela de Historia y en la Sección de Historia de la Cultura de la Escuela de Estudios Generales de la Universidad de Costa Rica.

Correo electrónico: romagu_02@yahoo.com 


\section{El estudio de la muerte en el islam: Una filosofía de la vida}

\section{Resumen}

Este trabajo es un ensayo interpretativo sobre la muerte en el islam, las creencias religiosas y las prácticas sociales. El estudio de la muerte en el islam se aborda como una filosofía de la vida. Por ello se analizan algunas de las obras de Sigmund Freud, como Totem y Tabú y El Malestar de la Cultura, así como La Revolución de la Esperanza. Hacia una Tecnología Humanizada, de Erich Fromm. Para comparar con los aspectos psicoanalíticos de los autores mencionados, se estudia la obra del filósofo Séneca De Brevitate Vitae (De la Brevedad de la Vida) y se compara con algunos libros cristianos sobre la necesidad de prepararse para la muerte, como por ejemplo la Imitación de Cristo de Tomás de Kempis y las más importantes obras musulmanas al respecto. En el islam el creyente y fiel seguidor del al-Qur'an y de las enseñanzas del Profeta Muhammad en la Sunna (dichos y hechos del Profeta) no debe temer a la muerte y debe prepararse para enfrentarla, con la esperanza de la vida en el más allá (al-Akhira). En este ensayo se analizan también los conceptos sufíes (místicos del islam) sobre la muerte y la esperanza que tienen de unirse a Allah en esta vida o en al-Akhira. Los sufíes por sus prácticas místicas están siempre preparados para la muerte, para gozar de Allah y de todas las bienaventuranzas del al-Janna (el Paraíso). Sus enseñanzas han servido de inspiración para muchos.

\section{Study of Death in Islam: A Life Philosophy}

\begin{abstract}
This paper is an interpretative essay about death in Islam, as well as religious beliefs and social practices. The study of death in Islam is analysed as a philosophy of life. For this reason, some works dealing with psychoanalis are used in this paper, such as those by Sigmund Freud, and Erich Fromm. In order to compare some themes developed by psychoanalisis, Seneca's De Brevitate Vitae is also studied, because he insisted in the need to be prepared for death. Seneca's teachings about being prepared for death are also compared with some Christian books, such as the Imitation of Christ, by Thomas of Kempis, as well as some of the most important sufi (mystics of Islam) works. All of this is aimed to study the need to be prepared for death. In Islam, believers and faithful followers of the Qur'an and Prophet Muhammad's teachings in the Sunna (sayings and deeds of the Prophet) shouldn't be afraid of death and should be prepared to face it because they have the hope of life in the hereafter (al-Akhira). This paper also studies the sufis' concepts about death and the hope they have to become one with God, to be united with Allah, either in this life or in alAkhira. Because of their mystical practices, sufis are always prepared to face death and also to enjoy Allah and all the promises contained in the Qur'an and the Sunna of a better life in al-Janna (the Paradise). Sufis' teachings have become an inspiration to many other Muslims.
\end{abstract}

Palabras clave: Islam, psicoanálisis, filosofía, muerte, sufíes.

Keywords: Islam, psychoanalysis, philosophy, death, sufis. 
El estudio de la muerte en el islam lleva a una filosofía de la vida. Sin duda este análisis nos hace más conscientes de la inmediatez de la muerte. Nos enseña con claridad que la vida es una fracción y por ello debemos vivirla lo mejor posible, al mismo tiempo que nos alerta la consciencia de ser más sensibles al dolor de los demás, de lo perecedero de lo material y lo rápido que se llega al fin. El lector cuidadoso de este ensayo podrá sentir lo que con palabras no se puede expresar y así obtener una mejor comprensión del valor de las religiones y en este caso concreto de la grandeza del islam. Esta religión nos manifiesta en la muerte la importancia de la vida para prepararse para el al-Akhira, la pequeñez de este mundo pasajero y la eternidad de la vida futura. En mi condición de cristiano católico no dejo de admirar las extraordinarias enseñanzas del al-Qur'an y de los Ahadith $^{1}$ del Profeta Muhammad que nos muestran nuestra insignificancia y el paso transitorio de la existencia ante la realidad inexorable de la muerte. ${ }^{2}$

¿Qué somos en este mundo? Quizá no más que sombras pasajeras, como las nubes. Nada queda, nada permanece. Por ello las religiones monoteístas, como el islam, enfatizan en la preparación para la vida en el al-Akhira, en el más allá. Para el ser humano, desde los tiempos más remotos, la muerte ha marcado la gran diferencia entre la existencia y el no ser. Los más diversos investigadores, filósofos y teólogos a lo largo de la historia y más recientemente los psicoanalistas, se han preguntado por la vida, por la existencia y por el más allá.

Sigmund Freud, por ejemplo, con su habitual interpretación psicoanalítica de la vida, de los sueños y de tantos otros asuntos naturales al ser humano, asimismo escribió sobre la actitud ante la muerte. ${ }^{3}$ En primer lugar señala que 
el ser humano desde los tiempos más remotos creía que se encontraba dispuesto a enfrentar la muerte, a considerarla como algo natural y como el desenlace obvio de la vida y que

cada uno de nosotros era deudor de una muerte a la Naturaleza y debía de hallarse preparado a pagar la deuda y que la muerte era cosa natural indiscutible e inevitable (Freud, 2001, p. 178)

Sin embargo, argumenta que el ser humano se comporta de otra forma y quiere prescindir de la muerte, silenciarla, eliminarla de la vida. En términos generales asegura que pensamos poco, o casi nada en la muerte, en nuestra muerte, sobre todo.

La muerte propia es, desde luego, inimaginable, y cuantas veces lo intentamos podemos observar que continuamos siendo en ello meros espectadores. Así, la escuela psicoanalítica ha podido arriesgar el aserto de que, en el fondo, nadie cree en su propia muerte, o lo que es lo mismo, que en lo inconsciente todos nosotros estamos convencidos de nuestra inmortalidad (Freud, 2011, p. 178).

En el mundo civilizado, cuando se trata de la muerte o el posible fallecimiento de otra persona, por lo general, se evita mencionar este asunto cuando el que va a morir puede oírle. También es natural que el hombre civilizado muestre sensibilidad y cortesía hacia la persona que está presta a su defunción. Si no lo hiciera, la sociedad le reclamaría esa actitud y desfachatez. Sin embargo, aún la mayor de las delicadezas no evita la muerte de muchos seres. Pero desde lo inconsciente nos sentimos conmovidos por la muerte de otra persona y al mismo tiempo defraudados en nuestras esperanzas. Freud da a entender que desde lo inconsciente el hombre se 
percata de su final inevitable, como el que tendrá cualquier otra persona. Este psicoanalista asimismo enfatiza la actitud del ser humano de considerar a la muerte como algo casual, como el accidente, la enfermedad, la vejez, y al mismo tiempo intenta rebajar a la muerte de la categoría de la necesidad, a un simple azar (Freud, 2011, p. 179).

Por lo anterior Freud explica que es común que la gente tome frente al muerto la actitud de admiración hacia alguien que ha llevado a cabo una tarea muy difícil. Por lo general se le exime de culpa y se le perdonan todas sus faltas. Por ello es justificado que en las oraciones fúnebres y en las inscripciones en la sepultura se le honre y se le ensalce.

La consideración al muerto - que para nada la necesita - está para nosotros por encima de la verdad y, para la mayoría de nosotros, seguramente por encima de la consideración a los vivos. Esta actitud convencional del hombre civilizado ante la muerte queda complementada por nuestro derrumbamiento espiritual cuando la muerte ha herido a una persona amada, el padre o la madre, el esposo o la esposa, un hijo, un hermano o un amigo querido. Enterramos con ella nuestras esperanzas, nuestras aspiraciones y nuestros goces; no queremos consolarnos y nos negamos a toda sustitución del ser perdido. Nos conducimos entonces como los asras, que mueren cuando mueren aquellos a quienes aman (Freud, 2011, pp. 179-180).

Como es factible observar, estas explicaciones freudianas de las actitudes del hombre frente a la muerte de un ser querido, se dan en todas las civilizaciones. El islam no es, por lo tanto, una excepción. Los musulmanes toman actitudes semejantes en el sufrimiento a las de otros seres humanos 
de otras civilizaciones y por ello también la tendencia desde lo inconsciente de excluir la muerte, lo que lleva asimismo a muchas renuncias y exclusiones. De hecho, se da el miedo a la muerte, sea en el islam, o en cualquier otra religión, o en general en cualquier ser humano. Sobre este último punto; es decir, cualquier ser humano, Freud explica que es casi siempre por el sentimiento de culpabilidad (Freud, p. 188). Desde lo inconsciente algunos saben morir y algunos otros inclusive matar a sus semejantes, con lo cual se despierta la consciencia de enfrentarse a la muerte. ${ }^{4}$ En todo ello la guerra hace evidente la muerte de muchas personas y con frecuencia en pocas horas, por lo cual ya no es posible negarla, sino que el ser humano debe enfrentarla, debe creer en ella (Freud, 2011, p. 181).

Freud luego analiza las dos actitudes ante la muerte: la primera la que se podría atribuir al hombre primordial, al hombre de la Prehistoria y la segunda, la que se ha conservado en los seres humanos, pero escondida e invisible para nuestra conciencia, en estratos profundos de la propia vida anímica. La primera actitud ante la muerte, la del hombre primordial, está basada en algunas inducciones e hipótesis, pues no se conoce con certeza. Sin embargo, Freud afirma que los medios y la información de que dispone proporcionan datos seguros. La actitud del hombre primordial no fue unitaria, sino llena de contradicciones y aún así tomó muy en serio la muerte y la reconoció como la supresión de la vida. Al mismo tiempo también la negó y la redujo a la nada. Estas contradicciones le llevaron a tener una actitud ambivalente. Su posición respecto de la muerte del extraño, del otro, de su enemigo, era diametralmente opuesta a su actitud ante su propia muerte. Para él, el deceso de los demás le era agradable, pues suponía el aniquilamiento de algo odiado. Según Freud, el hombre primordial no tenía originalmente ningún remordimiento en provocar la muerte de los otros, de sus enemigos. ${ }^{5}$ 
Posteriormente, cuando se enfrentó a la defunción de sus seres queridos y tomó mayor conciencia de la muerte, empezó a desarrollar los sentimientos de culpabilidad y de remordimiento por las muertes que causaba a sus enemigos. Tanto la historia del hombre primordial, como luego toda la historia de la humanidad, se han caracterizado por las muertes violentas. La historia universal es la historia de la guerra, de la muerte violenta, de la imposición de unos sobre otros. El hombre primordial, cuando empezó a tener remordimiento, comenzó a desarrollar las religiones que, sin duda, crean ese sentimiento de culpabilidad, de pena y llevan a la prohibición del asesinato y de muchas otras formas violentas de la muerte. Al respecto Freud escribió:

El oscuro sentimiento de culpabilidad que pesa sobre la Humanidad desde los tiempos primitivos, y que en algunas religiones se ha condensado en la hipótesis de una culpa original, de un pecado hereditario, no es probablemente más que la manifestación de una culpa de sangre que la Humanidad primordial echó sobre sí. En mi libro Totem y Tabú, ${ }^{6}$ siguiendo las indicaciones de W. Robertson Smith, Atkinson y Darwin, he intentado inferir la naturaleza de esta antigua culpa, y opino que todavía la doctrina cristiana actual nos hace posible inducirla. Si el Hijo de Dios tuvo que sacrificar su vida para redimir a la Humanidad del pecado original, este pecado tuvo que ser, según la ley del Talión, una muerte, un asesinato. Sólo esto podía exigir como penitencia el sacrificio de una vida. Y si el pecado original fue una culpa contra Dios Padre, el crimen más antiguo de la Humanidad tuvo que ser un parricidio, la muerte del padre primordial de la primitiva horda humana, cuya imagen mnémica fue transfigurada en divinidad (Freud, 2011, pp. 182-183). 
Freud explica que, para el hombre primordial, la muerte propia era inimaginable, probablemente como lo es para muchos de nosotros hoy día. ${ }^{7}$ Sin embargo, al enfrentar la muerte de un ser querido, su esposa, su hijo, o algún otro ser muy cercano, experimentó un gran dolor y le abrió la posibilidad de tener conciencia de que él mismo también podía morir. Por ello se rebeló contra esta idea, esta posibilidad, pues como Freud sostiene, cada uno de aquellos seres amados era un trozo de su propio y amado yo. Sin embargo, esos seres amados eran asimismo algo ajeno y extraño a él, por lo tanto, enemigos y odiados al mismo tiempo. ${ }^{8}$ Esto dio origen a una ambivalencia de los sentimientos de que los seres amados eran también sus enemigos que habían despertado sentimientos enemigos. ${ }^{9}$

Para este mismo psicoanalista, cuando el hombre primordial vio el cadáver de uno de sus seres queridos, desarrolló o inventó los espíritus, con lo cual la muerte no era el final, sino que había algo más allá, que continuaba con uno o varios espíritus. ${ }^{10}$ Esto dio origen posteriormente a la idea de la supervivencia después de la muerte, a llegar a lo que ofrecen las religiones, en especial las reveladas. Obviamente, en la consolidación de las grandes religiones, se pasa por toda una gama de creencias en la vida espiritual, en el más allá, pues puede explicarse en la transmigración de las almas, con lo que entonces han perpetuado el pasado. Pero todas las religiones con sus creencias en la vida futura insisten en que la muerte de esta vida, no es el término de la existencia. 
La segunda actitud ante la muerte es la que se ha conservado en los seres humanos pero escondida, oculta. Freud se pregunta: ¿Cómo se conduce nuestro inconsciente ante el problema de la muerte? Y la respuesta es que se manifiesta casi exactamente igual que en el hombre primordial. De manera que el hombre primitivo pervive inmutable en nuestro inconsciente. Al respecto escribió:

Así, pues, nuestro inconsciente no cree en la propia muerte, se conduce como si fuera inmortal. Lo que llamamos nuestro inconsciente -los estratos más profundos de nuestra alma, constituidos por impulsos instintivos - no conoce, en general, nada negativo, ninguna negación -los contrarios se funden en él - y, por tanto, no conoce tampoco la muerte propia, a la que sólo podemos dar un contenido negativo. En consecuencia, nada instintivo favorece en nosotros la creencia en la muerte. Quizá sea éste el secreto del heroísmo. El fundamento racional del heroísmo reposa en el juicio de que la vida propia no puede ser tan valiosa como ciertos bienes abstractos y generales (Freud, 2011, p. 188).

Pero también en nuestro inconsciente hay muchas maldiciones e instintos que suprimen a todos aquellos que estorban nuestro camino, o que nos han hecho daño, o que nos han ofendido. Inconscientemente hay impulsos hostiles, y el impulso a desearles la muerte

y nuestro inconsciente asesina, en efecto, incluso por pequeñeces... ya que todo daño inferido a nuestro omnipotente y despótico yo es, en el fondo, un crimen læsæ majestatis (Freud, 2011, p. 189). 
En resumen, Freud considera que nuestro inconsciente es tan inaccesible a la representación de la muerte propia, como lo es al mismo tiempo sanguinario contra los extraños y ambivalente con relación a los seres queridos, como lo fue en el hombre primordial. Pero nos hemos alejado mucho del hombre primordial en nuestra actitud convencionalmente civilizada ante la muerte. Por todo lo anterior concluye con las siguientes palabras:

Recordemos la antigua sentencia: Si vis pacem, para bellum. Si quieres conservar la paz, prepárate para la guerra. Sería de actualidad modificarlo así: Si vis vitam, para mortem. Si quieres soportar la vida, prepárate para la muerte (Freud, 2011, p. 192).

Para muchos musulmanes, pero también para los seguidores de otras religiones, el soportar la vida significa prepararse para la muerte, pero también la esperanza en la vida en el más allá (al-Akhira para los musulmanes) en al-Janna (el Paraíso) y en la resurrección (Yawm alQiyama). Desde el punto de vista del psicoanálisis y las interpretaciones de Freud, es en última instancia el temor a la muerte, tal como lo explicó en su Totem y Tabú. Citamos la traducción al portugués de esta obra:

"Uma explicação adicional para a maldade que se atribui às almas se encontraba no medo instintivo que se tem delas, medo que, por sua vez, é o resultado do medo da morte". [Una explicación adicional para la maldad que se atribuye a las almas se encontraba en el miedo instintivo que se tiene de ellas, miedo que, a su vez, es el resultado del miedo a la muerte] (Freud, 2011, p. 108). 
Erich Fromm (2007, pp. 18-34), otro destacado autor del psicoanálisis, contribuye al concepto de resurrección con gran profundidad, pero no el desarrollado por el cristianismo, ni por extensión, podríamos decir, por el islam. Debido a la profundidad de sus conceptos, de sus aportaciones originales, en lugar de parafrasear sus opiniones, mejor leamos el fragmento completo:

Este concepto de transformación personal o social nos permite e incluso nos obliga a redefinir el sentido de resurrección, sin referencia alguna a sus implicaciones teológicas en el cristianismo. Resurrección en su nueva significación -para la cual el significado cristiano sería una de sus posibles expresiones simbólicas - no es la creación de otra realidad después de la realidad de esta vida, sino la transformación de esta realidad encaminada a aumentar la vida. El hombre y la sociedad resucitan a cada momento en el acto de esperanza y de fe del aquí y el ahora. Cada acto de amor, de consciencia y de compasión es resurrección; cada acto de pereza, de avidez y de egoísmo es muerte. La existencia nos enfrenta en cada momento con la alternativa entre resurrección y muerte, y en todo momento respondemos. La respuesta no consiste en aquello que decimos o pensamos, sino en lo que somos, en el modo en que obramos, en el lugar en que nos desenvolvemos (Fromm, 2007, p. 28).

Tanto Freud como Fromm analizan estos aspectos desde el punto de vista del psicoanálisis. Para comprender la concepción de la muerte y los ritos funerarios en el islam, es importante también tener presente que la filosofía ha desarrollado asimismo muchos conceptos interesantes. Por ejemplo, Lucio Anneo Séneca en el siglo I de nuestra era, en su De Brevitate Vitae 
(De la Brevedad de la Vida) (2013) explica que el ser humano debe aprender a vivir y cuando lo logra se prepara entonces para la muerte. Esto mismo señala el islam. El creyente debe prepararse para la muerte y no temerle, pues la esperanza de una vida futura en el al-Akhira es mayor que el dolor de la muerte. El perverso y el infiel, por el contrario, temen a la muerte por el castigo que tendrán en el más allá. Séneca, por otra parte, nos indica que debe vivirse con intensidad, siempre pensando en el presente, pues el pasado ya no se puede cambiar y el futuro es incierto. Al respecto así escribió:

Al mismo tiempo, la espera, es el máximo impedimento para vivir, ya que mientras está pendiente del mañana, pierdes el día de hoy. Te preocupas de los proyectos que están en manos de la suerte, pero te olvidas de los que tienes entre manos. ¿A dónde miras?, ¿a dónde quieres llegar? Todos los acontecimientos que están por llegar son inciertos, vive el momento presente. Aquí el mayor de los poetas, Virgilio, inspirado por un divino temor, canta este himno saludable: "El día más hermoso, en la vida de los desgraciados humanos, es el primero que huye.” ¿Por qué dudas?, dijo, ¿por qué te retrasas? Si no lo aprovechas, el tiempo huye y aunque estés muy ocupado igualmente huirá. Así pues se lucha contra la velocidad del tiempo, como se lucha contra la velocidad de un torrente que no siempre se ha aprovechado en su rápida marcha (Séneca, 2013, pp. 30-31).

La intensidad no significa que el trabajo, o las actividades del comercio, o de la política, o cualquier otra, impidan al hombre tener espacios para reflexionar, para vivir para sí mismo, para meditar, para pensar. Solo si se vive con esas posibilidades del diálogo interior, logra el hombre prepararse para la muerte. Recordemos que esto mismo señala el islam. Séneca critica a todos aquellos que reclaman que la vida es muy breve. Este filósofo 
afirma entonces que la vida no es breve si se vive a plenitud. Esto es, que cada quien debe tener tiempo para sí mismo y que cada quien se prepare para la muerte. Es factible notar que estos mismos principios los han desarrollado otros filósofos, pensadores y teólogos en el islam, en el cristianismo y en otras religiones. Por ejemplo, recordemos que muchos siglos después de Séneca, Tomás de Kempis (siglo XIV) en su Imitación de Cristo, entre tantos consejos que da a los cristianos, así a hombres de religión que habitan un claustro, como a los hombres comunes, está siempre el principio de:

Busca tiempo a propósito para estar contigo, y piensa con frecuencia en los beneficios de Dios (De Kempis, 1985, p. 26).

Tomás de Kempis asegura entonces que en la soledad y en el silencio se logra la meditación, la reflexión interna y así:

El que se aparta de sus amigos y conocidos consigue que se le acerquen Dios y sus santos ángeles (De Kempis, 1985, p. 27).

Por medio de esa meditación, de la reflexión interna, se logra no ver ni reprochar los asuntos negativos de los demás, pues los defectos propios pueden ser aún mayores. Por ello todos los cristianos deben meditar:

y estudiemos en prepararnos mejor para morir (De Kempis, 1985, p. 25).

La similitud con el pensamiento de Séneca es evidente en varios aspectos, aunque uno es más en el nivel filosófico, mientras el otro lo es en la esfera religiosa para salvar el alma. En el islam los sufíes (místicos) desarrollaron toda 
una serie de planteamientos para llegar a Dios, para unirse con El en esta vida, como se explicará más adelante.

Volviendo a Séneca, él también critica a todos aquellos que están siempre angustiados y que dicen que nunca han tenido un minuto de descanso, que nunca han tenido un momento para sí mismos. Entre ellos menciona al Emperador Augusto, y a muchos otros que por la política y las ocupaciones de la administración pública no han podido descansar. Asegura que esos que nunca han logrado tener un momento de reflexión, de diálogo interno, no han vivido con intensidad, en el sentido explicado anteriormente. A lo largo de sus vidas no se han preparado para la muerte.

Entre otros casos que señala se puede mencionar el de los que por sus múltiples actividades comerciales y sus frecuentes viajes no encuentran un momento para sí mismos. De igual forma critica a aquellos que se pasan en grandes fiestas y que se dan a la bebida y a otros vicios, pues en esas actividades no logran tener momentos de reflexión interna, sino solo tiempo para los demás en los convites. También se opone a los vanidosos que se pasan con el barbero todo el tiempo para arreglarse el cabello, para que quede bien parejo, o para disimular lo más posible algunos indicios de calvicie. En estas ocupaciones constantes y distraídos de sí mismos no encuentran tiempo para prepararse para la muerte. Séneca critica a aquel que se pasa en los baños públicos muchas horas entretenido en asear el cuerpo y que cuando termina la jornada diaria de esos entretenimientos sus esclavos lo cargan hasta la silla y llega al colmo de preguntar si está sentado (Séneca, 2007, p. 39). En esto, que Séneca nos da a entender como una actividad superficial, se alcanzan tales niveles de distracción que un hombre así entretenido y ocupado no dispone de tiempo para la vida, para 
sí mismo y la reflexión interior. Este filósofo nos explica que un hombre así es como que no tuviera conciencia de sí mismo. Por ello cuando llega la muerte nota que la vida ha sido muy breve, pues no se ha preparado para morir. Para referirse a todos los casos anteriores escribió las siguientes líneas:

La vejez oprime sus ánimos todavía pueriles y llegan a ella inexpertos y desarmados; nada en efecto han previsto; de repente cayeron en ella (la vejez) con una actitud negativa, no saben enfrentarse a ella cotidianamente. Del mismo modo que, o bien un discurso, o una lectura o una intensa reflexión a veces confunden a los viajeros y no se dan cuenta de que han llegado a la meta antes de lo previsto, así es el camino de la vida que todos recorremos con la misma velocidad, pues tanto que estemos vigilantes, como si estamos durmiendo, como si estamos ocupados, no nos damos cuenta hasta que llegamos al final (Séneca, 2007, p. 31).

Más adelante en su obra, De Brevitate Vitae, Séneca reflexiona que a todos ellos los ha movido una cobardía ante la muerte y sienten un gran pavor de morir, no tanto por la muerte en sí, sino por la forma en que les fue arrebatada la vida. Enseguida escribe:

Gritan a viva voz que ellos fueron realmente necios, porque no vivieron realmente, y si por casualidad salieran de su enfermedad, entonces dicen que vivirán en total descanso. Piensan entonces cuán frustradamente prepararon aquellas cosas, que luego no supieron disfrutar de ellas, y en qué vacío ha quedado todo su trabajo (Séneca, 2007, p. 35). 
¿Quién es el más indicado para vivir intensamente y prepararse para la muerte? Se pregunta Séneca y su respuesta es que es el filósofo, el sabio, el que encuentra momentos para el diálogo interior, que vive también intensamente para sí mismo y logra prepararse para la muerte. Por ello nos dice que "el espacio que vivimos no es vida sino tiempo". El que ha logrado vivir de esa forma, cuando llega la muerte no le causa temor y se encuentra preparado.

Todo lo que hasta aquí se ha dicho es válido para todos los seres humanos indistintamente de la cultura o religión que impregnen sus vidas. En el islam la preparación y meditación sobre la muerte es principalmente desde el punto de vista religioso y para salvar el alma. Así habla el al-Qur'an para toda la humanidad, lo mismo que los Ahadith (dichos y hechos) del Rasul Allah (El Enviado de Dios). Los sufíes están preparados para la muerte y la esperan con ansiedad para llegar a Allah y gozar de Él y de todas las bienaventuranzas marcadas por el amor de Dios a toda la humanidad (al-Nas) y el amor del sufí a Allah. Para los sufíes una de las formas de conocer a Dios y llegar a Él era por el amor total a Allah por medio del Ma rifa Qalbiyya (el conocimiento por el corazón, por el amor). Por todo lo anterior los místicos del islam están preparados para la muerte.

En el islam el piadoso es aquel que se prepara para la muerte y por lo tanto no teme morir. Para efectos de este ensayo tomemos un ejemplo de los piadosos en el islam, que no temen a la muerte, ni al dolor que lleva a la defunción. Muchos de ellos cuando nace un ser humano se entristecen, pues infieren los muchos años que le pueden faltar para llegar a Allah. Mas si en cambio muere un ser humano se alegran, pues de esta manera, afirman, está más cerca de Dios. Al respecto los sufíes escribieron numerosos trabajos y poemas muy variados sobre este asunto de no temer 
a la muerte, pues se encuentran preparados para enfrentarla con la esperanza de una vida mejor en el al-Akhira. Esto ocurrió en todas las latitudes del Dar al-Islam y en las distintas épocas. Por ejemplo, Mansur al-Hallaj (m. 922) escribió:

Mi muerte constituye mi vida, pues veo a Dios al descubierto, directamente Él me ha construido una morada en la eternidad (Citado por Massingnon, 2007, p. 36).

También al-Hallaj escribió:

La muerte está sobre vosotros como un vigía pronto os transportará a todos fuera de aquí.

Soy un pájaro, este (cadáver) era mi jaula era mi prisión y la camisa de mi mortaja.

Doy gracias a Dios que me ha salvado y me ha construido en las alturas una residencia (Citado por Massingnon, 2007, p. 37).

De igual forma podemos citar estos otros versos de al-Hallaj:

Matadme y quemadme. En mis huesos perecederos

encontraréis el secreto de mi Amigo, en los

[repliegues de las (almas) supervivientes

olvidar acordase de mi Señor es un pecado capital] (Citado por Massingnon, 2007, p. 49). 
En términos generales los sufíes no temen a la muerte, están siempre preparados para ir a gozar de Allah por la eternidad. Asimismo, confían plenamente en Dios, por lo que desarrollaron el concepto de Tawakkul Allah (la confianza total en Allah). Esta confianza total en Dios significa que si el Creador decreta su muerte, el sufí estará satisfecho, pues de esta forma llegará más pronto a Allah. Los sufíes también creen que para el justo la muerte es algo que se desea, pues pone fin a los dolores y angustias de esta vida y abre, en cambio, la recompensa y los deleites en el alAkhira. ${ }^{11}$ El concepto del Tawakkul Allah asimismo significa que el místico del islam no se preocupa, no se atormenta por las cosas terrenales, pues ya ha renunciado a todo lo mundano. No tendrá su pensamiento ocupado en otras cosas que no sean en meditar, pensar en Allah, en alabar su santo nombre y en rezar constantemente. Esa es la devoción del sufí. ${ }^{12}$ Por ello, el místico no se preocupa si tendrá alimentos, agua, o una morada para el día siguiente. Si Dios quiere proveer, entonces comerá, tomará líquidos y habitará en una vivienda. Pero si Allah no desea para él todo eso, el sufí no se desvela, ni se mortifica y por lo tanto continúa en su pensamiento absoluto (Dhikr) en Allah y en el Tawakkul Allah.

Todo lo referente al Tawakkul Allah puede resumirse en una historia que con frecuencia se menciona cuando se explica este asunto de la confianza total en Dios. La historia nos informa - y la vamos a parafrasear - que un día un sufí al cruzar sobre un puente el río Tigris, cayó al agua y se estaba ahogando. Entonces otro hombre que se encontraba a la vera de la corriente y que lo miró en esa condición angustiosa le preguntó: 
_“¿Quiere que vaya a pedir ayuda?” y el sufí que se estaba ahogando le contestó:

-"No".

Entonces el hombre que estaba en la orilla del río le hizo otra pregunta:

_“¿Quiere que le ayude?”

El sufí contestó:

-"No".

- “QQuiere ahogarse?” volvió a inquirir el observador.

El sufí volvió a responder de forma negativa y alcanzó a decir:

-"No".

En ese momento el hombre que observaba toda la situación le hizo otra pregunta más:

-“Entonces, ¿que es lo que quiere?”

A lo que el sufí logró contestar:

-"Que se haga la voluntad de Allah"

La historia tiene un final feliz porque lograron sacar al místico, al hombre de religión que había caído al río. Sin embargo, independientemente del desenlace que hubiera tenido esta historia, lo importante es que muestra, con una posición extrema, la práctica del Tawakkul Allah. 
Otro importante concepto del sufismo es del fana' (autoaniquilación, anulación total del $n a f s,{ }^{13}$ o ego para rendirse completamente en Allah). La meta última y principal del sufí es la unión con Dios, la que intenta lograr por medio del amor. El amor está por encima de la gnosis y conduce al éxtasis, a la embriaguez de Dios, lo que lleva también a la autoaniquilación (fana'), máxima expresión de la búsqueda de la unión con Dios por el amor. Por todo lo anterior el místico del islam no teme a la muerte y se encuentra preparado para enfrentarla.

Debido a que los sufíes plantearon la experiencia mística como un sendero (tariqa) diferente, para lograr el acercamiento y la unión con Dios por el amor, tuvieron que enfrentar la oposición de los 'ulama' (líderes religiosos, juristas). Esto llevó posteriormente también a las numerosas discusiones y a las disputas entre razón y revelación. En estas controversias los místicos jugaron un papel de considerable importancia, pues su comunicación personal con Dios formaba parte de su respuesta a este problema. Por estos motivos el sufí no teme a la muerte, pues considera que esta lo puede acercar más rápido a Allah. Si así es, entonces para él la muerte será bienvenida. ${ }^{14}$

A lo largo de los siglos ha habido muchos místicos en el islam. Como estos asuntos los he tratado en otra parte, no es necesario repetirlos aquí. ${ }^{15}$ Bástenos solo recordar, para los propósitos de este trabajo, que un destacado sufí, seguidor de la doctrina del monismo existencialista (Wadat al-Wujud) de Ibn 'Arabi, fue el persa Jalal al-Din Rumi (m. 1273). Rumi nació en Persia, pero vivió gran parte de su vida en Konya, en la actual Turquía. ${ }^{16} \mathrm{Su}$ obra más valiosa fue Mathnawi, en la cual desarrolló con originalidad y profundidad los más importantes temas sufíes. Debemos indicar que como parte del desarrollo de sus ideas del Wahdat al-Wujud 
(monismo existencialista), Rumi se identificó con la naturaleza, siguiendo el sistema de transmigración. Buscó obtener la dicha, no en la vida después de la muerte en el Paraíso, ofrecido por Dios de acuerdo con el Corán, sino en la autointegración en la persona de la divinidad. Con relación a la integración con Dios, Rumi, escribió las siguientes líneas:

He muerto como animal para convertirme en planta, he muerto como planta para hacerme animal, y he muerto como animal para hacerme hombre. ¿Por qué temer? ¿Cuándo la muerte me produjo mengua? ${ }^{17}$

Una vez más moriré como hombre para remontarme a la bienaventuranza angélica; pero también trascenderé al ángel y seguiré mi sendero: todo, excepto Dios, perece.

Cuando ya haya sacrificado mi alma angélica me convertiré en lo que el pensamiento no puede concebir.

Ojalá deje de existir, porque la inexistencia proclama con melodías de órgano: nosotros volveremos a Dios (Nicholson, 1975, p. 146). ${ }^{18}$

De todo lo explicado de la experiencia mística en el islam, no hay duda de que el sufí desea un acercamiento y una unión total con Allah, por lo que la muerte no representa para él un desafío, ni un temor, pues con ella puede llegar más pronto a esa unión mística con Allah. Para los místicos del islam el concepto de la muerte y enfrentarla tienen una dimensión diferente que para los otros musulmanes. Recordemos que el al-Qur'an insiste en que el justo, el piadoso, no debe temer a la muerte, como ya se ha indicado. Ese temor solo debe experimentarlo el injusto, el perverso, por el castigo que 
le aguarda. Del fragmento anterior de Rumi podemos observar esa nueva idea de la muerte, de la transmigración figurada. Es figurada, pues no puede ser de otra forma, ya que el islam no acepta la creencia en la transmigración de las almas. Al mismo tiempo Rumi desarrolla el concepto de la inexistencia, que le lleva a la unión espiritual con Allah. Notemos también la última parte del fragmento citado de Rumi, que es sin duda un principio coránico, nosotros volveremos a Dios. El al-Qur'an dice:

إنا لله و إنا إليه راجعون

[Ciertamente a Allah pertenecemos y ciertamente a Él regresaremos] (Al-Qur'an, p. 156).

Por todo lo explicado queda claro que el musulmán piadoso y fiel seguidor del al-Qur'an y de la Sunna (dichos y hechos de Muhammad) no debe temer a la muerte, debe prepararse para enfrentarla y llegar a gozar de las bienaventuranzas del al-Janna (el Paraíso) prometido por Allah, cuyas explicaciones están contenidas tanto en el al-Qur'an como en los Ahadith del Profeta Muhammad. Por otra parte, el islam señala que el perverso, el infiel, teme a la muerte por el castigo que le espera en el más allá (alAkhira). De entre los musulmanes los que están mejor preparados para enfrentar a la muerte y lograr el al-Janna son los sufíes. Esto es debido a sus mortificaciones constantes, a su meditación permanente, a sus oraciones, al desapego total de todo lo material, a la supresión del nafs (ego), a las prácticas del Dhikr (pensamiento constante en Allah) y al Tawakkul Allah (la confianza total en Dios), entre otras prácticas. Debido a todo ello se han preparado para la muerte y están dispuestos a aceptarla en cualquier momento, pues es una de las vías más rápidas para llegar a unirse a Allah y gozar de Su presencia.

\section{Reflexiones finales y conclusión}


El islam desarrolló una serie de creencias religiosas sobre la muerte y la vida futura, así como prácticas sociales. Los ritos funerarios en el islam van desde cerrar los ojos del difunto (si murió con ellos abiertos), el lavado ( $g h u s l$ ) ritual del cadáver, perfumarlo, amortajarlo (Kafan) con telas que cubran la totalidad del cuerpo, las oraciones fúnebres (jana 'iz), el cortejo fúnebre, y el funeral (janaza) hasta el entierro ( $q a b r$ ) propiamente dicho. Al musulmán se le entierra directamente en la tierra, de su costado derecho y con la cara mirando hacia la qibla (dirección de la oración) del islam; es decir, hacia la Meca. Las prácticas sociales con relación a la muerte y los muertos consisten en visitar a las familias dolientes, solidarizarse con todos los parientes del difunto, mostrar respeto, asistir al funeral y a las oraciones (salat, janaza) por el difunto. Todas estas creencias religiosas y prácticas sociales nos permiten aborda el estudio de la muerte en el islam como una filosofía de la vida, ya que, durante toda la existencia, el individuo debe prepararse para la muerte. Se estudiaron también en este ensayo las interpretaciones psicoanalíticas de Sigmund Freud y Erich Fromm sobre la muerte y el inconsciente, así como los aportes de Séneca y sus recomendaciones en su De Brevitate Vitae de que el hombre se prepare para la muerte, que medite y tenga tiempo para la reflexión interior, lo que se analizó en este trabajo, así como los grandes aportes de los místicos del islam al respecto. 
'Abduh, Muhammad. (1929). Tafsir al-Qur'an al-Karim. El Cairo.

\section{Referencias}

'Arifi, Muhammad 'Abdul Hai. (2001). The Islamic Way in Death. Karachi: Idaratul-Qur'an.

'Attar, Farid al-Din, Muntiq al-Ta'ir. (1971). The Conference of the Birds. Shambhala, Boulder.

Abdel-Kader, Ali Hassan. (1976). The Life, Personality and Writings of alJunayd, Luzac \& Company. Londres.

Abdul Rauf, Muhammad. (2008). The Qur'an. Introduction and Sample Texts. Washington: The Islamic Center.

Abdul Rauf, Muhammad. (1974). The Sacred Texts of Islam: Al-Qur'an and the Hadith (Introduction and Sample). Lagos, Nigeria: Islamic Publications Bureau.

Abu Rayya, Mahmud. (1980). Adwa' 'ala al-Sunna al-Muhammadiyya, Dar al-Ma'arif, El Cairo.

Ahmad, Muhammad Mushtaq. (2008). "The notions of Dar al-Harb and Dar al-Islam in Islamic jurisprudence with special reference to the Hanafi school”. En Islamic Studies, 47, (1), pp. 5-37.

Al-'Iqqad, 'Abbas Mahmud. (1969). Al-Falsafa al-Qur'aniyya, Dar alKitab al-‘Arabi. Beirut.

Al-'Usaymi al-Tamimi, Salih Muqbil. (2004). Bida 'al-Qubur. Anwa'uha wa Ahkamuha, Dar al-Fadila, Riyad.

Al-Baghdadi, Abu Mansur 'Abd al-Qahir Ibn Tahir Ibn Muhammad. (1973). Al-Farq Bayna al-Firaq. Beirut. 
Al-Baghdadi, al-Hafiz al-Imam Abu Bakr 'Abd Allah Ibn Muhammad Ibn 'Ubayd. (2002). Dhikr al-Mawt, editado por Abu 'Ubayda Mashhur bn. Hasan Al Salman, Maktabat al-Furqan, Ajman. Emiratos Árabes Unidos.

Al-Bakri, Abu 'Ubayd. (1968). Jughrafiyyat al-Andalus wa Uruba min Kitab al-Masalik wa al-Mamalik, editado por 'Abd al-Rahman 'Ali al-Hajji, Dar al-Irshad wa al-Nashr wa al-Tawzi‘. Beirut.

Al-Bakri, Abu 'Ubayd. (1965). Kitab al-Masalik wa al-Mamalik. (Kitab Mughrib fi Dhikr Bilad Ifriqiyya wa al-Maghrib), Description de l'Afrique Septentrionale, editado y trandución al francés por Mac Guckin de Slane, Librairie d'Amerique et d'Orient Adrien Maisonneuve. París.

Al-Baladhuri, Abu al-Hasan Ahmad Ibn Yahya. (1959). Ansab al-Ashraf, editado por M. Hamidullah, Dar al-Ma'arif. El Cairo.

Al-Baladhuri, Abu al-Hasan Ahmad Ibn Yahya. (1971). Ansab al-Ashraf, editado por Max Schloessinger, The Hebrew University Press. Jerusalén.

Al-Baladhuri, Abu al-Hasan Ahmad Ibn Yahya. (1938). Ansab al-Ashraf, editado por Max Schloessinger, The Hebrew University Press. Jerusalén.

Al-Baladhuri, Abu al-Hasan Ahmad Ibn Yahya. (1883). Ansab al-Ashraf, editado por W. Ahlwardt, Griefswald.

Al-Baladhuri, Abu Hasan Ahmad Yahya. (1936). Ansab al-Ashraf, editado por S.D. Goitein, The Hebrew University Press. Jerusalén. 
Al-Baladhuri, Abu Hasan Ahmad Yahya. (1968). Futuh al-Buldan, editado por M.J. de Goeje, E.J. Brill, Leiden.

Al-Bayanuni, Ahmad 'Izz al-Din. (1973). Al-Amr bi-al-Ma 'ruf wa al-Nahy 'an al-Munkar, Maktabat al-Huda, Alepo. Siria.

Al-Bayanuni, Ahmad 'Izz al-Din. (1972). Al-Fitan, Maktabat al-Huda, Alepo. Siria.

Al-Bukhari, Muhammad Ibn Isma'il Abu 'Abd Allah al-Ju'fi. (1312). AlSahih. El Cairo.

Al-Bukhari, Muhammad Ibn Isma'il al-Mughira. (s. f.). Sahih al-Bukhari, traducción al español por Isa Amer Quevedo, Fundación Benéfica Abdullah Rashid al-Zeer. Kuwait.

Al-Darimi, 'Abd Allah Ibn 'Abd al-Rahman. (2000). Musnad al-Darimi al-Ma'ruf bi-Sunan al-Darimi, Dar al-Mughni, Dar Ibn Hazm, Riyad. Beirut.

Al-Darimi, 'Abd Allah Ibn 'Abd al-Rahman (s. f.). Sunan al-Darimi, wa huwa al-Imam al-Kabir Abu Muhammad 'Abd Allah Ibn 'Abd alRahman Ibn al-Fadil Ibn Bahram Ibn 'Abd al-Samad, al-Tamimi, Dar Ihya' al-Sunna al-Nabawiyya.

Al-Dimashqi, Imam al-Hafiz Ibn Kathir. (2005). Qisas al-Anbiya’, editado por 'Adil Abu al-'Abbas, Maktaba al-Qur'an, Maktaba al-Qur'ran. El Cairo.

Al-Dinawari, Abu Hanifa Ahmad Ibn Dawd. (1960). Al-Akhbar al-Tiwal, editado por A.M. Amir y G. al-Shayyal, Wizarat al-Thaqafa wa'lIrshad al-Qawmi. El Cairo. 
Al-Ghazali, Abu al-Hamid. (2009). Al-Maqsad al-Asna fi Sharh Ma'ani Asma' Allah al-Husna, editado por Fadlu A. Shihadi, Dar alMashriq, Beirut, 1971. The Ninety-Nine Beautiful Names of God, traducción al inglés por David B. Burrell y Nazih Daher, The Islamic Texts Society. Cambridge.

Al-Ghazali, Abu al-Hamid. (1971). Ihya' 'Ulum al-Din [La Revivificación de las Ciencias Religiosas], "The Duties of a Muslim to a Muslim”, en John Williams, Themes of Islamic Civilization, University of California Press, Berkely, Los Angeles, Londres.

Al-Ghazali, Abu al-Hamid. (2012). Inner Dimensions of Islamic Worship, traducido del árabe al inglés de Ihya' 'Ulum al-Din, por Muhtar Holland, The Islamic Foundation, Leicestershire. United Kingdom.

Al-Ghazali, Abu al-Hamid. (2006). Path to Sufism. Deliverance from Error. Al-Munqidh min al-Dalal, traducido del árabe al inglés por R.J. McCarthy, S.J., Fons Vitae. Louisville, Kentucky.

Al-Ghazali, Abu Hamid. (2007). Al-Durra al-Fakhira (La Perla Preciosa), traducción del árabe de Lucien Gauthier, versión española de Agustín López y María Tabuyo, Limpergraf. Barcelona.

Al-Ghazali, Abu Hamid Muhammad. (1967). Tahafut al-Falasifa, AlMaktaba al-Kathulikiyya. Beirut.

Al-Ghazali, Abu Hamid Muhammad. (1989). The Remembrance of Death and the Afterlife. Kitab Dhikr al-Mawt wa Ma Ba'dahu, de Ihya' 'Ulum al-Din, traducción al inglés por T.J. Winter, The Islamic Texts Society. Cambridge. 
Al-Ghazali, Abu Hamid. (2002). On Knowing this World and the Hereafter, traducción al inglés por Muhammad Nur 'Abdus Salam. Chicago: Great Books of the Islamic World.

Al-Ghazali, Sheikh Mohamed. (2008). Islam, our religion, traducción al inglés de Amal Galal, ISESCO. Trípoli.

Al-Ghursi, Muhammad Salih. (2002). Al-Sunna al-Nabawiyya: hujjiya wa Tadwinan, Dar Nur al-Maktabat, Mu'assasat al-Rayyan. Beirut.

Al-Hallaj, Ibn Mansur. (1974). The Tawasin. The Great Sufi Text on the Unity of Reality, traducción al inglés de Aisha Abd al-Rahman atTarjumana. Berkeley y Londres.

Al-Ibiyari, Ibrahim. (1982). Ta'rikh al-Qur'an, Dar al-Kitab al-Lubnani. Beirut.

Al-Kawwaz, Muhammad Karim. (2006). Min Asatir al-Awwalyn ila Qisas al-Anbiya’, Al-Intishar al-'Arabi. Beirut.

Al-Khaymi, Talal Makki. (1429). Kitab Hayat al-Barzakh: Ahl al-Mawt wa Ahl al-Qubur wa Ahl al-Du'a', Maktabat Malik Fahd alWataniyya. Meca.

Al-Mas'udi, Abu al-Hasan 'Ali b. al-Husayn b. 'Ali. (1981). Al-Tanbih wa al-Ishraf, Dar wa Maktaba al-Hilal. Beirut.

Al-Mujtaba. (1964). Sunan al-Nasa ’i: al-Mujtaba, Maktabat wa Matba'at Mustafa al-Babi al-Halabi. El Cairo.

Al-Nadim, Abu al-Faraj Ibn Abi al-Ya'qub al-Warraq. (1970). Kitab alFihrist, editado por Gustav Flügel, Leipzig, 1871 (reimpresión, Beirut, 1964). The Fihrist of al-Nadim, traducción al inglés de Bayard Dodge. New York: Columbia University Press, 
Al-Nasa'i, Abu 'Abd al-Rahman Ahmad Ibn Shu'ayb 'Ali Ibn Bahr Ibn Sinan. (1990). Tafsir al-Qur'an al-'Azim, Maktabat al-Sunna. El Cairo.

Al-Nawawi, Imam Abu Zakariyya' Yahya. (1995). El Paso hacia el Paraíso, Dichos del Enviado de Dios, traducción al español por Ahmad M. Safi. Maryland: Amana Publications.

Al-Sa'ih, 'Abd al-Hamid. (1979). Ahammiyyat al-Quds fi al-Islam, Wizarat al-Awqaf wa'l-Shu'un wa'l-Muqaddasat al-Islamiyya, 'Amman.

Al-Sadiqi, Muhammad. (1972). Rasul Allah fi al-Kutub al-Samawiyya, Mu'assasat al-A ‘alami li’l-Matbu'at. Beirut.

Al-Saghir, Muhammad Husayn 'Ali. (1983). Ta'rikh al-Qur'an, Al-Dar al'Alamiyya, Muqaddasat al-Islamiyya. Beirut.

Al-Sulami, al-Imam al-Zahid Abu 'Abd Allah 'Abd al-Rahman Muhammad bn. Al-Husayn bn. Muhammad bn. Musa. (1960). Kitab Tabaqat al-Sufiyya, editado por Johannes Pedersen, E.J. Brill.

Al-Suyuti, al-Hafiz Jalal al-Din 'Abd al-Rahman Ibn Abi Bakr. (1967). AlItqan fi 'Ulum al-Qur'an, editado por Muhammad Abu Fadl Ibrahim. El Cairo.

Al-Suyuti, al-Hafiz Jalal al-Din 'Abd al-Rahman Ibn Abi Bakr. (1964). Ta 'rikh al-Khulafa', editado por Muhammad Muhyi al-Din 'Abd alHamid, Maktaba Nahdat Misr. El Cairo.

Al-Suyuti, al-Hafiz Jalal al-Din. (s. f.). Ta'rikh al-Khulafa', Dar al-Fikr. Beirut. 
Al-Suyuti, Jalal al-Din Muhammad Ibn Ahmad al-Muhli y Jalal al-Din Ibn 'Abd al-Rahman Ibn Abi Bakr. (2004). Tafsir al-Jalalayn, Maktaba al-Safa. El Cairo.

Al-Tabari, Muhammad Ibn Jarir. (1879). Ta'rikh al-Rusul wa al-Muluk, editado por M.J. de Goeje, E.J. Brill. Leiden.

Al-Tabari, Muhammad Ibn Jarir. (s. f.). Ta'rikh al-Umam wa al-Muluk, Dar al-Ma'arif. El Cairo.

Al-Tabari, Muhammad Ibn Jarir. (1969). Tafsir al-Qur'an. Jami ‘ al-Bayan 'an Ta'wil al-Qur'an, editado por Mahmud Muhammad Shakir y Ahmad Muhammad Shakir, Dar al-Ma‘arif bi-Misr. El Cairo.

Al-Tirmidhi, Abu 'Isa Muahmmad b. 'Isa b. Sawra b. Shaddad. (1937). AlJami ‘ al-Sahih, editado por Ahmad Muhammad Shakir, (Volúmenes I y II), Muhammad Fu'ad Abd al-Baqi (Volumen III), Ibrahim ‘Atwa 'Iwad (Volúmenes IV y V). El Cairo.

Al-Tirmidhi, Muhammad Ibn 'Isa. (1950). Al-Mukhtasar fi al-Shama’il alMuhammmadiyya wa Sharhuha li-Abi 'Isa al-Tirmidhi, Matba'at Misr.

Al-Tirmidhi, Muhammad Ibn 'Isa. (1987). Mukhtasar al-Shama'il alMuhammadiyya, Maktabat al-Adab. El Cairo.

Al-Tirmidhi, Muhammad Ibn 'Isa. (1931). Sahih al-Tirmidhi, editado por 'Abd al-Wahid Muhammad al-Tazi, al-Matba'at al-Misriyya bi-alAzhar. El Cairo.

Al-Tirmidhi, Muhammad Ibn 'Isa. (1965). Sunan al-Tirmidhi wa huwa alJami ‘ al-Sahih, Al-Maktaba al-Salafiyya. Medina. 
Anónimo. (1993). "Ibn Madja". En First Encyclopaedia of Islam, E.J. Brill, Leiden, 1993, Vol. III.

Anónimo. (1953). "Ibn Maja”. En Shorter Encyclopaedia of Islam. New York: Cornell University Press, Ithaca.

Anónimo. (s. f.). Death and Death Ceremonies, Peer Mohamed Ebrahim Trust, Karachi.

Anónimo. (s. f.). Nahj al-Balagha, Tahrike Tarsile Qur'an, Elmhurst.

Ansari, Abdolah. (2009). Del alma, el corazón y el intelecto. Himnos y tratados, traducción de Clara Janés y Ahmad Taheri. Madrid: Trotta.

Arasteh, A. Reza. (1984). Rumi, el persa, el sufí. Barcelona: Paidós.

Arberry, John. (1965). Revelation and Reason in Islam. Allen and Unwin. Londres.

Arberry, John. (1979). Sufism. An Account of the Mystics of Islam. Londres: Mandala Books.

Arberry, John. (1953). The Legacy of Persia. Oxford: Oxford University Press.

Arnaldez, R. (1965). "Ma'rifa”. En Encyclopaedia of Islam, (2). E.J. Brill, Leiden.

Ayyub, Fadila al-Shaykh Hassan. (2002). Al-Hadith fi 'Ulum al.Qur'an wa al-Hadith, Dar al-Salam. El Cairo.

Ayyub, Sa'id. (2001). Zawjat al-Nabi. Qira'tun fi Tarajim Ummahat alMu'minin fi Harakat al-Da 'wa, Al-Fath al-I'lam al-'Arabi. El Cairo. 
Bacqué, Jean-Louis y Aksel Tíbet. (1996). Cimetières et traditions funéraires dans le monde islamique, Société d'Histoire Turque. Ankara.

Bahjat, Ahmad. (s. f.). Anbiya' Allah, Matbu'at al-Jadida.

Bahr al-'Ulum, 'Izz al-Din. (1978). Al-Taqlid fi Shari 'a al-Islamiyya, Dar al-Zahra' li’1-Taba'a wa al-Nashr, wa al-Tawzi'. Beirut.

Baqli, Ruzbihan. (1997). The unveiling Secrets. Diary of a Sufi Master, traducción de Carl W. Ernst. Chapel Hill: Parvardigar Press.

Ben Cheneb, Mohammed. (1953). “Al-Darimi”. En Shorter Encyclopaedia of Islam. New York: Cornell University Press, Ithaca.

Beneito, P. (1996). El Secreto de los Nombres de Dios. Murcia.

Burckhardt, T. (1980). Esoterismo Islámico. Madrid: Taurus Ediciones.

Burke, O. M. (1975). Among the Dervishes, A first-hand account of a Wsterner's travels through the land of the Sufis. E.P. Dutton \& Co., Inc.

Castañeda, J. C. (2009). “De la muerte y las muertes en el Mundo Islámico: Algunas reflexiones sobre la muerte de Muhammad, el Profeta”. En Estudios de Asia y África, 44, (3), pp. 491-525.

Corbin, H., et.al. (1978). “La Filosofía Islámica desde sus orígenes hasta la muerte de Averroes”. En Brice Parain, Historia de la Filosofia. Del Mundo Romano al Islam Medieval, pp.236-358.

Cruz, M. (1981). Historia del Pensamiento en el Mundo Islámico. Madrid: Alianza. 
Cruz, M. (1963). La Filosofía Árabe. Madrid: Alianza.

Farmadi, 'Abd al-Hayy. (1991). Al-Mawt fi al-Fikr al-Islami, Dar alI'tisam. El Cairo.

Freud, S. (2011). El malestar en la cultura. Madrid: Alianza Editorial.

Fromm, E. (2007). La revolución de la esperanza. Hacia una tecnología humanizada. D. F., México: Fondo de Cultura Económica.

Gardet, L. (1965). "Djanna”. En Encyclopaedia of Islam, (2). E.J. Brill, Leiden.

Goldziher, I. (1993). “Ahmad b. Muhammad b. Hanbal”. En First Encyclopaedia of Islam. Leiden: E.J. Brill.

Goldziher, I. (1993). "Fiqh”. En First Encyclopaedia of Islam. Leiden: E. J. Brill.

Goldziher, I. (1967). Muslim Studies, traducción al inglés por C.R. Barber y S.M. Stern. Londres: George Allen \& Unwin Ltd.

Goldziher, I. (1971). Muslim Studies, traducción al inglés por C.R. Barber y S.M. Stern. Londres: Allen and Unwin.

Guénon, R. (1992). Esoterismo Islámico y Taoismo, traducción de Victoria Argimón. Barcelona: Ediciones Obelisco.

Halevi, L. (2006). Muhammad's Grave: Death Rites and the Making of Islamic Society. New York: Columbia University Press.

Hawi, S. (1974). Islamic Naturalism and Mysticism. A Philosophic Study of Ibn Tufayl's Hayy Bin Yaqzan. Leiden: E.J. Brill. 
Husaini, S.A. (1970). The Pantheistic Monism of Ibn al-'Arabi. Muhammad Ashraf. Lahore.

Ibn 'Ali, Zayd. (1966). Musnad al-Imam Zayd, Dar Maktabat al-Hayat. Beirut.

Ibn 'Ali, Zayd. (1981). Musnad al-Imam Zayd: wa huwa ma Rawahu 'an Abihi 'an Jaddihi wa Yusammi al-Majmu' al-Fiqhi li-Dhikr, Dar alKutub al-'Ilmiyya. Beirut.

Ibn Abi al-Dunya al-Qurashi, 'Abd Allah Ibn Muhammad. (2000). Kitab al-Qubur, editado por Tariq Muhammad al-'Umudi, Maktabat alGhuraba' al-Athariyya. Medina.

Ibn al-'Arabi, Abu Bakr. (1996). Kitab Shawahid al-Jilla, edición y estudio de Muhammad Ya'la. Madrid: Consejo Superior de Investigaciones Científicas.

Ibn al-'Arabi, Muhyi al-Din. (s. f.). 'Aridat al-Ahwadhi: bi-Sharh Sahih al-Tirmidhi, Dar al-Kutub al-'Ilmiyya. Beirut.

Ibn al-'Arabi, Muhyi al-Din. (1939). Risalat al Quds, editado por Miguel Asín Palacios. Madrid: Imprenta E. Maestre.

Ibn al-Athir, 'Izz al-Din. (1965). Al-Kamil fi al-Ta'rikh, editado por C.J. Tornberg, E.J. Brill. Leiden.

Ibn al-Banna', Muhammad. (1948). Risala fi al-Anwa', editado por P.J. Renaud. París.

Ibn Anas, Malik. (2009). Al-Muwatta', traducción al español de Hajj Abdul Ghani Melara Navío. Granada: Madrasa Editorial. 
Ibn Bajja (Avempace). (1997). Tadbir al-Mutawahhid, (El Régimen del Solitario), introducción, traducción al español y notas de Joaquín Lomba. Madrid: Editorial Trotta.

Ibn Barrajan. (2000). Sharh Asma' Allah al-Husna (Comentario sobre los Nombres más Bellos de Allah), edición crítica y estudio por Purificación de la Torre. Madrid: Consejo Superior de Investigaciones Científicas.

Ibn Bashkuwal, Abu al-Qasim Khalaf. (1995). Kitab al-Qurba ila Rabb al'Alamin, (El Acercamiento a Dios) estudio, edición crítica y traducción al español de Cristina de la Puente. Madrid: Consejo Superior de Investigaciones Científicas.

Ibn Hanbal, Ahmad. (1313). Musnad. El Cairo.

Ibn Hazm, 'Ali Ibn Ahmad Ibn Sa'id. (1964). Al-Fasl fi al-Milal wa alAhwa' al-Nihal. El Cairo.

Ibn Hisham, Abu Muhammad 'Abd al-Malik. (2005). Sirat al-Nabi, Dar al-Tala'i', Madinat Nasr. El Cairo.

Ibn Hisham, Abu Muhammad 'Abd al-Malik. (s. f.). Sirat al-Nabi, editado por Muhammad Muhyi al-Din 'Abd al-Hamid, Dar al-Ma'arif, alQahira. El Cairo.

Ibn Kathir, Isma'il Ibn 'Umar. (1966). Al-Bidayya wa al-Nihayya, Maktabat al-Ma'arif. Beirut.

Ibn Kathir, Isma'il Ibn 'Umar. (1966). Al-Bidayya wa al-Nihayya, Maktabat al-Ma'arif. Beirut. 
Ibn Kathir, Isma'il Ibn 'Umar. (1964). Al-Sirat al-Nabawiyya, editado por Mustafa 'Abd al-Wahid, 'Isa al-Babi al-Halabi. El Cairo.

Ibn Kathir, Isma'il Ibn 'Umar. (1964). Al-Sirat al-Nabawiyya, editado por Mustafa 'Abd al-Wahid, 'Isa al-Babi al-Halabi. El Cairo.

Ibn Kathir, Isma'il Ibn 'Umar. (1968). Qisas al-Anbiya', Dar al-Kutub alHaditha. El Cairo.

Ibn Kathir, Isma'il Ibn 'Umar. (1968). Qisas al-Anbiya', Dar al-Kutub alHaditha. El Cairo.

Ibn Kathir, Isma'il Ibn 'Umar. (1966). Tafsir al-Qur'an, Dar al-Andalus li'l-Tiba'a wa al-Nashr. Beirut.

Ibn Kathir, Isma'il Ibn. (1966). 'Umar, Tafsir al-Qur'an, Dar al-Andalus li’l-Tiba'a wa al-Nashr. Beirut.

Ibn Sirin, Muhammad. (2004). Tafsir al-Ahlam, Dar al-Fajr li’1-Turath. El Cairo.

Ibn Taymiyya, Taqi al-Din Ibn 'Abd al-Halim. (1977). Tafsir Surat al-Nur, Maktabat al-Manar al-Islamiyya. Kuwait.

Izutsu, Toshihiko. (1993). Sufismo y Taoísmo. Madrid: Siruela.

Jabaliyya, Ahmad. (1983). Al-Qur'an wa 'Ilm al-Falak, Al-Dar al'Arabiyya li'l-Kitab, Túnez.

Jassus, Muhammad Ibn Qasim. (1927). Min Sharh al-Shama’il alTirmidhiyya, Maktabat wa Matba'at M.A. Sabih. El Cairo.

Khoury, Adel-Th. (2000). Los Fundamentos del Islam. Barcelona: Crítica. Knappert, Jan. (1985). Islamic legends. Histories of the Heroes, Saints and Prophets. Leiden: E.J. Brill. 
López, M. E. y Marín, R. (en prensa). Muerte y ritos funerarios en el islam. Estudio sobre las creencias religiosas y las prácticas sociales.

Marín, R. (1983). “El Islam, una religión”. En Crónica, 3, pp.81-90.

Marín, R. (1985). “El Sufismo, Misticismo Islámico”. En Tiempo Actual, $10,(38)$, pp.43-57.

Marín, R. (1982). "La Escatología Musulmana: Análisis del Mahdismo”. En Cuadernos de Historia, 44.

Marín, R. (1986). El Islam: Ideología e Historia, Alma Mater. San José, Costa Rica: Editorial de la Cooperativa de Libros de la Universidad de Costa Rica.

Marín, R. (1983). Introducción a los Estudios Islámicos. San José: Nueva Década.

Marín, R. (1989). “Mahdyzm - Muzulmanski Mesjanizm”. En Collectanea Theologica, 59, (4), pp.137-144.

Marín, R. (1996). “Miejsce Dziecka W Rodzinie Musulmanskiej”. En Collectanea Theologica, 66, (3), pp.156-158.

Marín, R. (2002). “Mistyka Musulmanska”. En Eugeniusz Sakowicz, Czy Islam Jest Religia Terrorystow? Krakow: Homo Dei.

Marín, R. (1990). "Sufizm - mistycyzm islamu”. En Collectanea Theologica, 60, (1), pp.113-118.

Massignon, L. (2007). La Guerra Santa Suprema del Islam Árabe. Palma de Mallorca: Padma. 
Michon, J. (2000). Luces del Islam. Instituciones, arte y espiritualidad en la ciudad musulmana, traducción de Francesc Gutiérrez, Sophia Perennis, José J. de Olañeta, Editor. Palma de Mallorca.

Mora, F. (2011). Ibn 'Arabi. Vida y enseñanzas del gran místico andalusí. Barcelona: Editorial Kairós.

Najjar, 'Abd al-Wahhab. (1966). Qisas al-Anbiya', Mu’assasat al-Halabi wa Shirkahu li’1-Nashr wa al-Tanzwi‘. El Cairo.

Nawfal, 'Abd al-Razzaq. (1969). Yawm al-Qiyama, Maktabat Dar alSha‘b. El Cairo.

Nicholson, Reynold A. (1975). Poetas y Místicos del Islam, traducción al castellano de Fernando Valera. México: Ediciones Orión.

Nicholson, R. (1975). Los Místicos del Islam. México: Diana.

Nicholson, R. (1978). Studies in Islamic Mysticism. Cambridge: Cambridge University Press.

Nicholson, R. (1970). The Idea of Personality in Sufism. Muhammad Ashraf. Lahore.

Palmer, E.H. (1974). Oriental Mysticism. A treatise on Sufiistic and Unitarian Theosophy of the Persians. Londres: The Octagon Press Ltd.

Pareja, F. (1975). La Religiosidad Musulmana. México: Biblioteca de Autores Cristianos.

Rodinson, M. (1974). Mahoma. El nacimiento del Islam. México: Era.

Ruiz, M. (2002). La religión islámica: una introducción. México: El Colegio de México. 
Sadan, J. (2000). "On tombs and Holy Writ. Some methodological and lexicographical notes on burial concepts in Islamic figh (religious law), literature and practices". En Asher Ovandiah, editor, Milestones in the Arts and Culture of Egypt. Tel Aviv: Tel Aviv University.

Saeed, A. (1974). What happens after death. New Delhi: Dini Book Depot.

Séneca, L. A. (2013). De Brevitate Vitae (De la Brevedad de la Vida), traducción al español por Rosario Delicado. Madrid: Ediciones Antígona.

Sha'ban, Muhammad Isma‘il. (1978). Al-Ahadith al-Qudsi, Dirasat fi alSunna. Dar al-Matbu'at al-Dawliyya.

Shahata, 'Abd Allah Mahmud. (1972). Ta'rikh al-Qur'an wa al-Tafsir, AlHay’a al-Misriyya al-‘Ama li'l-Kitab. El Cairo.

Simpson, J. (1995). "Death and burial in the late Islamic Near East: some insights from archaeology and ethnography”, en Stuart Campbell and Anthony Green, editors, The Archaeology of Death in the Ancient Near East. Oxford: Oxbow Books.

Smith, J. \& Yazbeck, I. (2002). The Islamic Understanding of Death and Resurrection. Oxford: Oxford University Press.

Smith, M. (1977). An Introduction to Mysticism. New York: Oxford University Press.

Smith, M. (1928). Rabi' 'a, the Mystic and her Fellow-Saints in Islam. Cambridge: Cambridge University Press. 
Smith, M. (1976). The Way of the Mystics. The early Christian mystics and the rise of the Sufis. Londres: Sheldon Press.

Taboada, H. (2008). “Muertos y vivientes en el Islam”. En Estudios de Asia y África, 18, (3), pp.701-712.

Taymur, Ahmad, Muhammad Rasul Allah. Salla Allahu 'Alayhi wa Salam, Lajnat Nashr al-Ma'allafat al-Taymuriyya, El Cairo, 1966.

Torre, Purificación de la. (2000). Introducción a Ibn Barraŷan, Sharh Asma' Allah al-Husna, introducción, edición crítica y estudio de Purificación de la Torre. Madrid: Consejo Superior de Investigaciones Científicas.

Tritton, A.S. (1960). “Akhira”. En Encyclopaedia of Islam, (2). Leiden: E.J. Brill.

Wansbrough, J. (1977). Qur'anic Studies. Sources and Method of Scriptural Interpretation. Londres: Oxford University Press.

Watt, M. (1948). Free Will and Predestination in early Islam. Londres: Luzac.

Watt, M. (1953). Muhammad at Mecca. Oxford: Oxford University Press.

Watt, M. (1956). Muhammad at Medina. Oxford: Oxford University Press.

Watt, M. (1973). The Formative Period of Islamic Thought. Edinburgh: Edinburgh University Press. 
1. Para mayores detalles sobre los Ahadith del Profeta Muhammad véase: Lucas, Scott C., Constructive critics, hadith literature, and the articulation of sunni Islam. The legacy of the generation of $\mathrm{Ibn} \mathrm{Sa} \mathrm{Sa}^{\text {d }}$, Ibn Ma'in and Ibn Hanbal, E.J. Brill, Leiden, Boston, 2004.

2. Sobre la muerte en el islam recomendamos las siguientes obras, tanto primarias como secundarias: Fuentes primarias: Al-Hafiz alImam Abu Bakr 'Abd Allah Ibn Muhammad Ibn 'Ubayd alBaghdadi, Dhikr al-Mawt, editado por Abu 'Ubayda Mashhur bn. Hasan Al Salman, Maktabat al-Furqan, Ajman (Emiratos Árabes Unidos), 1423 H. (2002 d.C.). Abu Hamid Muhammad al-Ghazali, The Remembrance of Death and the Afterlife. Kitab Dhikr al-Mawt wa Ma Ba 'dahu, de Ihya' 'Ulum al-Din, traducción al inglés por T.J. Winter, The Islamic Texts Society, Cambridge, 1989. Fuentes secundarias: 'Abd al-Hayy Farmadi, Al-Mawt fi al-Fikr al-Islami, Dar al-I'tisam, El Cairo, 1991.Talal Makki al-Khaymi, Kitab Hayat al-Barzakh: Ahl al-Mawt wa Ahl al-Qubur wa Ahl al-Du'a', Maktabat Malik Fahd al-Wataniyya, Meca, 1429 H. José Carlos Castañeda Reyes, "De la muerte y las muertes en el Mundo Islámico: Algunas reflexiones sobre la muerte de Muhammad, el Profeta”, en Estudios de Asia y África, Vol. XLIV, Número 3, (140), 2009, pp.491-525. Leor Halevi, Muhammad's Grave: Death Rites and the Making of Islamic Society, Columbia University Press, New York, 2006. Roberto Marín Guzmán y Manuel Enrique López Brenes, Muerte y Ritos Funerarios en el Islam. Estudio sobre las creencias religiosas y las prácticas sociales, de próxima publicación. Hernán G.H. Taboada, "Muertos y vivientes en el Islam", en Estudios de Asia y África, Vol. XLIII, Número 3 (137), 2008, pp. 701-712. 
3. Véase Sigmund Freud, El malestar en la cultura, Alianza Editorial, Madrid, 2011, pp. 178-192.

4. Sigmund Freud, Totem e Tabu. Algumas correspondências entre a vida psíquica dos selvagens e a dos neuróticos, Coleção L\&PM Pocket, Porto Alegre, Brasil, 2013, p. 74.

5. Para mayores detalles, véase: Freud, El malestar en la cultura, pp. 182-183.

6. Para mayores detalles véase Freud, Totem e Tabu. Algumas correspondências entre a vida psíquica dos selvagens e a dos neuróticos, passim. Respecto de las prohibiciones impuestas de una generación a otra, entre los hombres primitivos o primordiales, Freud escribió las siguientes líneas que citamos de la traducción de su Totem y Tabú al portugués: Em primeiro lugar, diríamos então que não tem sentido perguntar aos selvagens pelo motivo real de suas proibições, pela gênese do tabu. Segundo nosso pressuposto, eles devem ser incapazes de comunicar algo a respeito, pois esse motivo seria "inconsciente" para eles. No entanto, de acordo com o modelo das proibições obsessivas, constuímos a história do tabu da meneira que segue. Os tabus seriam proibições antiquíssimas, um dia impostas de fora a uma geração de homens primitivos, o que significa, portanto, que elas provavelmente lhes foram inculcadas de maneira violenta pela geração mais antiga. Essas proibições afetaram atividades para as quais existia uma forte inclinação. As proibições se conservaram de geração a geração, talvez apenas em consequência da tradição baseada na autoridade parental e social. Mas talvez, nas organizações posteriores, elas já tenham se "organizado” como uma parcela de patrimônio psíquico herdado, 
As questões de saber se existem tais "ideias inatas" e se elas produziram a fixação do tabu sozinhas ou em cooperação com a educação-quem poderia respondê-las justamente a propósito do caso em discussão? Freud, Totem e Tabu, p. 74.

7. Véase también: Freud, Totem e Tabu. Algumas correspondências entre a vida psíquica dos selvagens e a dos neuróticos, p. 108.

8. Véase también: Freud, Totem e Tabu. Algumas correspondências entre a vida psíquica dos selvagens e a dos neuróticos, pp. 105-109.

9. Para mayores detalles sobre estos asuntos, así como las explicaciones freudianas, más en términos del conflicto sentimental que surge a raíz de la muerte de los seres queridos del hombre primordial, que son al mismo tiempo extraños y odiados, véase: Freud, El malestar en la cultura, pp.183-185. Para más información sobre la crítica freudiana a los filósofos, debido a que estos han enfatizado más la posible meditación del hombre primordial sobre el enigma de la vida y la muerte, en lugar de los aspectos sentimentales, véase: Freud, El malestar en la cultura, pp.183-185. Véase también: Freud, Totem e Tabu. Algumas correspondências entre a vida psíquica dos selvagens e a dos neuróticos, pp. 105-109.

10. Freud, Totem e Tabu. Algumas correspondências entre a vida psíquica dos selvagens e a dos neuróticos, passim.

11. Para más información al respecto, véase: Thomas O'Shaughnessy, S.J., Muhammad's Thoughts on Death. A thematic study of the Qur'anic data, E.J. Brill, Leiden, 1969, p. 60. 
12. Para mayores detalles sobre la devoción del sufí, véase: Andrew Rippin, Muslims. Their Religious Beliefs and Practices, Routledge, Londres, New York, 2001, pp. 127-139.

13. Para mayor información sobre el nafs como alma y luego como ego, véase: E.E. Calverley, "Nafs", en Shorter Encyclopaedia of Islam, Cornell University Press, Ithaca, 1953, pp. 433-436.

14. Para mayores detalles al respecto de los sufies, o místicos del islam, véanse: John Arberry, Revelation and Reason in Islam, George Allen \& Unwin, Londres, 1965, pp. 103-105. Roberto Marín Guzmán, El Islam: Ideología e Historia, Alma Mater Editorial de la Cooperativa de Libros de la Universidad de Costa Rica, San José, 1986, p. 196. Roberto Marín Guzmán, "Razón y Revelación en el Islam", en Revista de Filosofía, Vol. XXII, números 55-56, 1984, pp.133-150, en especial pp. 138-139. Marshall G. Hodgson, The Venture of Islam, Chicago University Press, Chicago, 1974, Vol. I, pp. 404-405. Adel-Th. Khoury, Los Fundamentos del Islam, Herder, Barcelona, 2000, p. 252. Para mayores detalles sobre el sufí alJunayd véase: Ali Hassan Abdel-Kader, The Life, Personality and Writings of al-Junayd, Luzac and Company, Londres, 1976, pp. 3-8 y pp. 121-183. Montgomery Watt, The Formative Period of Islamic Thought, Edinburgh University Press, Edinburgh, 1973, passim, en especial pp.209-250. Montgomery Watt, Islamic Philosophy and Theology, Edinburgh University Press, Edinburgh, 1979, passim, en especial p. 59; p. 62; p. 69; p. 86. D.B. MacDonald, Development of Muslim Theology, Jurisprudence and Constitutional Theory, Russell \& Russell, New York, 1965, passim, en especial pp. 140 ss.; pp. 159-160; pp. 187-189; pp. 190-192; pp.194-200; p.231; pp. 201- 
205. Roberto Marín Guzmán, Kitab al-Bukhala' [El Libro de los Avaros] de al-Jahiz. Fuente para la Historia Social del Islam Medieval, El Colegio de México, México, 2001, passim, en especial pp. 163-177. Roberto Marín Guzmán, "La Mu tazila, escuela libre pensadora del Islam. Historia de una controversia teológica y triunfo del Ash 'arismo. Siglos IX y X”, en Estudios de Asia y África, Vol. XXXVIII, No. 1 (120), 2003, pp. 11-58. Véase también: Henri Corbin, et.al., "La Filosofía Islámica desde sus orígenes hasta la muerte de Averroes", en Brice Parain, Historia de la Filosofía. Del Mundo Romano al Islam Medieval, Siglo XXI, México, 1978, p. 332. Para mayores detalles sobre al-Junayd, véanse: Carl Brockelmann, History of the Islamic Peoples, Capricorn Books, New York, 1960, pp. 149-150. Abdel-Kader, The Life, Personality and Writings of al-Junayd, pp.171-178. Para un recuento detallado de las diversas obras de al-Junayd, véase: Nadim, Kitab al-Fihrist, The Fihrist of al-Nadim, Vol. I, pp. 487-488. También: Al-Imam alZahid Abu 'Abd Allah 'Abd al-Rahman Muhammad bn. Al-Husayn bn. Muhammad bn. Musa al-Sulami, Kitab Tabaqat al-Sufiyya, editado por Johannes Pedersen, E.J. Brill, Leiden, 1960, passim.

15. Véanse: Roberto Marín Guzmán, "Sufysim-Mistycyzm Islamu”, en Collectanea Theologica, (Varsovia, Polonia), Vol. LX, Fasc. 1, 1990, pp. 113-118. Roberto Marín Guzmán, "Un cuento sufí en Las Mil y Una Noches: la historia de Abu al-Hasan con Abu Ja'far el leproso. Análisis del contexto social y religioso del Islam Medieval", en Miscelánea de Estudios Árabes y Hebraicos, Vol. LI, 2002, pp. 91-111. Roberto Marín Guzmán, "El Sufismo, Misticismo Islámico", Tiempo Actual, Año X, Número 38, 1985, pp. 43-57. 
Marín Guzmán, El Islam: Ideología e Historia, passim, en especial pp. 191-202.

16. Para mayores detalles sobre Rumi, véase: A. Reza Arasteh, Rumi, el persa, el sufi, Paiados Orientalia, Barcelona, 1984.

17. Volvemos a insistir en la importancia de la muerte en el islam y en la práctica sufí de no temerle. Para mayores explicaciones sobre la muerte en el al-Qur'an y en la forma en que se manifiesta en el islam véase: Muhammad Ibn Sirin, Tafsir al-Ahlam, Dar al-Fajr li'lTurath, El Cairo, 2004, pp. 69-77.

18. Véanse también: Philip Hitti. Islam, Modo de Vida, Gredos, Madrid, 1973, p. 107. Marín Guzmán. El Islam: Ideología e Historia, p. 201. Marín Guzmán. "Razón y Revelación en el Islam”, p. 141. Véanse también: Ibn Mansur al-Hallaj, The Tawasin. The Great Sufi Text on the Unity of Reality, traducción al inglés de Aisha Abd al-Rahman at-Tarjumana, Diwan Press, Berkeley y Londres, 1974. John Arberry, Sufism. An Account of the Mystics of Islam, Mandala Books, Londres, 1979, pp. 60-61. Para mayores detalles al respecto véase: Reynold Nicholson, The Idea of Personality in Sufism, Muhammad Ashraf, Lahore, 1970, pp. 38-39. Véase también: Al-Husayn Ibn Mansur al-Hallaj, Kitab al-Tawasin, p. 175, citado por Nicholson. The Idea of Personality in Sufism, p. 39. Margaret Smith, The Way of the Mystics. The early Christian mystics and the rise of the sufis, Cambridge University Press, Cambridge, 1976. passim. Reynold Nicholson, Studies in Islamic Mysticism, Cambridge University Press, Cambridge, 1978, pp. 167 ss. A. Reza Arasteh, Rumi, el persa, el sufi, Ediciones Paidós, Barcelona, 1984, 
pp. 49 ss. Marín Guzmán, "El Sufismo, Misticismo Islámico”, pp. 43-57. Roberto Marín Guzmán, “Sufizm - Mistycyzm Islamu”, en Collectanea Theologica, Vol. LX, Fasc, 1, Varsovia, Polonia, 1989, pp.113-118. Marco Lucchesi, "A dança da unidade”, Beluce Bellucci, Cultura, Poder e Tecnologia: Africa e Asia face à Globalização, Editora da Universidade Candido Mendes, Rio de Janeiro, 2001, pp. XI/37-XI/44, en especial p. XI/42. Sami S. Hawi, Islamic Naturalism and Mysticism. A Philosophic Study of Ibn Tufayl's Hayy Bin Yaqzan, E.J. Brill, Leiden, 1974, pp.232 ss. Louis Massignon, The Passion of al-Hallaj. Mystic and Martyr of Islam, Princeton University Press, Princeton, 1982, pp.560 ss. S.A.Q. Husaini, The Pantheistic Monism of Ibn al-'Arabi, Muhammad Ashraf, Lahore, 1970. Toshihiko Izutsu, Sufismo y Taoísmo, Ediciones Siruela, Madrid, 1993, pp.268-291. Véase también: Ibn Sirin, Tafsir al-Ahlam, pp.420-421. También: Al-Sulami, Kitab Tabaqat al-Sufiyya, passim. Véanse también: Abdolah Ansari, Del alma, el corazón y el intelecto. Himnos y tratados, traducción de Clara Janés y Ahmad Taheri, Trotta, Madrid, 2009. Ruzbihan Baqli, The unveiling Secrets. Diary of a Sufi Master, traducción de Carl W. Ernst, Parvardigar Press, Chapel Hill, 1997. Titus Burckhardt, Esoterismo Islámico, Taurus Ediciones, Madrid, 1980. Omar Michael Burke, Among the Dervishes, A first-hand account of a Wsterner's travels through the land of the Sufis, E.P. Dutton \& Co., Inc., s.l.e., 1975. René Guénon, Esoterismo Islámico y Taoísmo, traducción de Victoria Argimón, Ediciones Obelisco, Barcelona, 1992. Fernando Mora, Ibn 'Arabi. Vida y enseñanzas del gran místico andalusí, Editorial Kairós, Barcelona, 2011. Toshihiko 
Izutsu, Sufismo y Taoísmo (Dos Volúmenes), traducción de Anne-

Hèlène Suárez, Ediciones Siruela, Madrid, 1997. Jean-Louis Michon, Luces del Islam. Instituciones, arte y espiritualidad en la ciudad musulmana, traducción de Francesc Gutiérrez, Sophia Perennis, José J. de Olañeta, Editor, Palma de Mallorca, 2000.

\section{Recibido: 18-diciembre-2015 \\ Aceptado: 21-marzo-2016}

Todos los derechos reservados. Universidad de Costa Rica. Esta revista se encuentra licenciada con Creative Commons Reconocimiento-NoComercialSinObraDerivada 3.0 Costa Rica. (CC BY-NC-SA 3.0 CR)

Correo electrónico: humanidades@ucr.ac.cr Sitio web: http://revistas.ucr.ac.cr/index.php/humanidades 